\title{
Evaluation of day time sleepiness using Epworth sleepiness score among medical students
}

\author{
Veena C N ${ }^{1}$, Tejaswi Meghana ${ }^{2, *}$, B C Vastrad ${ }^{3}$, Nandan T M ${ }^{4}$ \\ ${ }^{\mathbf{1}}$ Assistant Professor, Dept. of Physiology, Sambhram Institute of Medical Sciences and Research, K.G.F, Karnataka, ${ }^{2}$ Student, \\ ${ }^{3}$ Professor and HOD, Dept. of Physiology, PES Institute of Medical Sciences and Research, Kuppam, Andhra Pradesh, \\ ${ }^{4}$ Associate Professor, Dept. of Microbiology, Sambhram Institute of Medical Sciences and Research, K.G.F, Karnataka, India
}

*Corresponding Author:

Email: tejaswi.pothakamuri@gmail.com

Received: $25^{\text {th }}$ January, 2018

Accepted: $20^{\text {th }}$ April, 2018

\begin{abstract}
Introduction: Physiologic and cognitive function in humans vary considerably with the circadian rhythm, which also regulates the sleep cycle. Sleep is an active, repetitive and reversible behavior serving several different physiological functions. Medical students are a unique group of young adults whose academic commitments and lifestyle can have an impact on their sleep habits. Objectives: To evaluate day time sleepiness using Epworth sleepiness score among medical students.

Materials and Methods: The study population consisted of 130 first year MBBS students selected randomly based on their consent. Data was collected with the help of Epworth sleepiness scale.

Results and Conclusion: The present study demonstrated the presence of excessive day time sleepiness among $45 \%$ of the students. Since a strong relationship is evident between good sleep quality and high academic performance, measures to improve the sleep quality among medical students need to be focused.
\end{abstract}

Keywords: Sleep deprivation, Day time sleepiness, Epworth sleepiness score, Medical students.

\section{Introduction}

Physiologic and cognitive functions in humans vary considerably with the circadian rhythm, which also regulates the sleep cycle. ${ }^{1}$ Sleep is an active, repetitive and reversible behaviour serving several different functions, such as repair and growth, learning or memory consolidation, and restorative processes which occur throughout the brain and the body. ${ }^{2,3}$ Measures of health and well-being are strongly related to the quality than to the quantity of sleep.

Sleepiness is defined as the inability or difficulty in maintaining alertness during the major wake period of the day, resulting in unintended lapses into drowsiness or sleep and sleep deprivation is defined as obtaining inadequate sleep to support adequate daytime alertness. ${ }^{4}$ Sleep deprivation at varying occasions and durations can substantially impair cognitive, and emotional functions and recent evidences have indicated an important relationship between sleep patterns with learning abilities. ${ }^{1,5}$ Also sleep deprivation is associated with impaired glucose metabolism and relative insulin insensitivity, altered immune function, suggesting that sleep may play important host defense roles. ${ }^{6}$ Medical students are a unique group of young adults whose academic commitments and lifestyle can have an impact on their sleep habits. ${ }^{7}$ Many of them are sleep deprived because they go to sleep late and wake up for classes before adequate sleep is obtained. ${ }^{4}$ The continuous academic demand, escalating level of stress as well as the hectic schedule might be reason for irregular sleep/wake patterns and poor sleep quality. ${ }^{8}$ Sleepiness can be an obvious consequence of sleep deprivation, though it can be caused by other reasons, most commonly sleep disorders. ${ }^{4}$ Evidences from previous studies suggest inadequate sleep during night is mostly associated with day time naps. Daytime sleepiness is a major problem, exhibited by $50 \%$ of college students compared to $36 \%$ of adolescents and adults. ${ }^{9,10}$ It is an important clinical and public health concern and can lead to significant decrease in quality of life. Excessive daytime sleepiness is one of the principal symptoms of sleep disturbances and is more likely to occur in monotonous situations when alerting stimuli are absent, and it is associated with increased risk of accidents, such as when operating motor vehicles or other machinery, decreased productivity, and interpersonal problems. ${ }^{11,12}$ The severity of sleepiness can be quantified subjectively using Epworth sleepiness scale. The Epworth Sleepiness Scale (ESS) is a validated clinical tool widely used subjective method for assessing day time sleepiness. It is simpler, cheaper, and less time-consuming. It also attempts to measure the general level of daytime sleepiness over a recent period. ${ }^{13}$ The conceptual basis of the ESS involves a four-process model of sleep and wakefulness. ${ }^{14}$ Numerous studies conducted within the past decade have analyzed the deleterious effects of sleep deprivation on medical staff in various medical as well as surgical specialties. ${ }^{8}$ Napping in the lecture halls is commonly observed among the medical students but the prevalence rate of daytime sleepiness in this group is less well documented. The few prevalence studies available showed highly variable rates among college or university students, from as low as $4.1 \%$ in Japanese 
graduate students ${ }^{15}$ to as high as $42.4 \%$ in Brazilian medical school. ${ }^{16}$ Thus the present study is an attempt to evaluate day time sleepiness using Epworth sleepiness score among medical students PES Institute of Medical sciences and Research (PESIMSR), Kuppam, since this group are vulnerable to sleep deprivation.

\section{Materials and Methods}

The present cross sectional study was carried out at PESIMSR, Kuppam. The study population consisted of 130 first year MBBS students selected randomly based on their consent. Students with chronic sleep disorders, on medications for sleep disorders, on medications that leads to sleep, alcohol consumption, drug abuse were excluded. The ethical clearance was obtained from Institution Ethics Committee. Data was collected with the help of Epworth sleepiness scale (ESS), which is a self-administered questionnaire having eight questions. Here the students are asked to rate, on a 4-point scale (0-3) their usual chances of dosing off while they are engaged in eight different activities. Thus, the total score of the ESS ranges from 0 to $24 .{ }^{13}$ The higher the score, the greater the possibility the individual will fall asleep during the daytime prior to administering the questionnaire, the participants were explained regarding the purpose of study and were also informed that participation or otherwise in this study will not affect the relationship with either the researcher or the institution in which they are studying. License for the use of Epworth sleepiness scale (ESS-United States/English-Version of 16 Jan 15-Mapi, ID037309/ESS_AU10_eng_US1.doc.) and the consent from the study subjects who are willing to participate was obtained. After obtaining the consent they were divided into groups of 35 each and were made to sit in such a way that copying and discussion is not possible. The students were also informed not to mention their name in the form so that they feel free to give true information. The returned questionnaires were checked for completeness.

\section{Interpretation of ESS:}

0-5: Lower normal daytime sleepiness 6-10: Higher normal day time sleepiness 11-12: Mild excessive daytime sleepiness 13-15: Moderate excessive daytime sleepiness 16-24: Severe excessive day time sleepiness ${ }^{17}$

\section{Results}

The data was expressed as percentage. Out of 130 students, 55 students reported to have day time sleepiness.

Table 1: Grading of epworth sleepiness score

\begin{tabular}{|l|c|c|}
\hline \multicolumn{1}{|c|}{ Grading } & Number & Percentage \\
\hline Lower normal day time sleepiness(LNDS) & 11 & 8 \\
\hline Higher normal day time sleepiness (HNDS) & 65 & 50 \\
\hline Mild excessive day time sleepiness(MEDS) & 31 & 24 \\
\hline Moderate excessive day time sleepiness (MoEDS) & 21 & 16 \\
\hline Severe excessive day time sleepiness (SEDS) & 3 & 2 \\
\hline
\end{tabular}

Graph 1: Percentage distribution of students based on Epworth sleepiness score

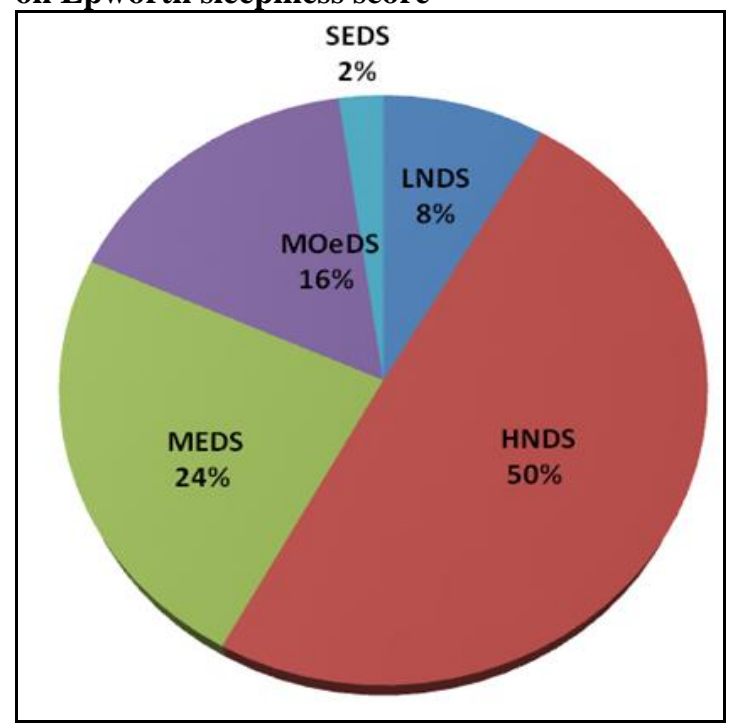

\section{Discussion}

Sleep is one of our basic needs.It is important for our physical intellectual and emotional health. ${ }^{3} \mathrm{We}$ all need sleep so as to work adequately the next day. However, the unanswered question is, how much sleep do we need? Sleep researchers do not seem to agree on how much we should sleep. With the new civilization, sleep restriction has become a global problem. Most young adults report sleeping on average approximately $7.5 \mathrm{~h} \mathrm{a}$ night on weekday nights and slightly longer, $8.5 \mathrm{~h}$ on weekends. ${ }^{6}$ Experiencing somnolence events during the day is natural. However, the worsening of this behavior can lead to unsatisfactory levels of sleep and related disorders, which can be characterized as excessive daytime sleepiness. According to the literature, both the difficulty in staying awake and alert during the day, and the increased subjective perception of sleep need are characterized as excessive daytime sleepiness. This disorder results in involuntary naps and lapses during sleep. Excessive daytime sleepiness (EDS) is linked to negative social, professional, and family effects, to a 
decrease in work and school performance, to low learning outcomes and to reductions in quality of life. Among pathological conditions EDS is a typical symptom of sleep disorders such as Obstructive Sleep Apnoea (OSA), narcolepsy, and idiopathic hypersomnia. Studies have reported that $2 \%$ of women and $4 \%$ of men in the general middle-aged population suffer from obstructive sleep apnoea. ${ }^{18}$ The present study demonstrated the presence of excessive day time sleepiness in 55 students $(45 \%)$ where as findings of Goel $\mathrm{N}$ et al showed that $10 \%$, Bahamman $\mathrm{A} \mathrm{S}$ et al showed that $22.4 \%$ and Zailinawati $\mathrm{AH}$ et al. showed that $35 \%$ of students had excessive day time sleepiness. ${ }^{5,19,20}$ The results of the present study is alarming as the percentage subjects with day time sleepiness has increased compared to previous studies. This increased prevalence of sleepiness in recent times may be due the change in the sleep habits.

\section{Conclusion}

Since a strong relationship is evident between good sleep quality and high academic performance. ${ }^{1}$ Measures to improve the sleep quality among medical students need to be focused. Measures like promoting living environment, providing health education on proper sleep hygiene and better schedulingof lectures are highly recommended for improvement in their academic performance.

Limitations of our Study: ESS is only a subjective method that can be used for EDS diagnosis, ${ }^{18}$ and does not act as a gold-standard test, so the prevalence of EDS found in this study might be overestimated. The diagnosis of EDS should be further validated by objective methods such as polysomnography. Also the sample population selected is restricted to first MBBS students. Further studies involving medical students of all phases and medical students of different medical colleges is required for knowing their sleep habits.

\section{References}

1. Mirghani HO, Mohammed OS, Almurtadha YM, Ahmed MS. Good sleep quality is associated with better academic performance among Sudanese medical students. BMC Research Notes. 2015;8:706. doi:10.1186/s13104-015-1712-9.

2. Pilcher JJ, Ott ES. The relationships between sleep and measures of health and well-being in college students: A repeated measures approach. Behav Med. 1998;23(4):170-7.

3. Entsarkamel M E I Desouky, JosephinAtef A. Lawend, Howida Abu Ellife M. Awed. Relationship between quality of sleep and academic performance Among Female Nursing Students. International Journal of Nursing Didactics. 2015;5(9). DOI: https://doi.org/10.15520/ijnd.2015.vol5.iss9.111.06-13

4. Hershner SD, Chervin RD. Causes and consequences of sleepiness among college students. Nature and Science of Sleep. 2014;6:73-84. doi:10.2147/NSS.S62907.
5. Curcio G, Ferlara M, De Gennaro L. Sleep loss, learning capacity and academic performance. Sleep Med Rev. 2006 Oct;10(5):323-37.

6. Goel N, Malhotra V, Tripathi Y. Sleep habits among first year medical students. J Evolution Med Dent Sci. 2016;5(38):2276-2278. DOI:10.14260/jemds/2016/529

7. Ahmed S Ba Hammam, Abdulrahman M Alaseem, Abdulmajeed A Alzakri, Alojohara S Almeneessier, Munir M Sharif. Therelationship between sleep and wake habits and academic performance in medical students: a cross-sectional study. BMC Medical Education, 2012;12(1): 1 .

8. PA Giri, MP Baviskar, DB Phalke. Study of Sleep Habits and Sleep Problems among Medical Students of Pravara Institute of Medical Sciences Loni, Western Maharashtra, India, Ann Med Health Sci Res. 2013 Jan-Mar;3(I):5 1-54.

9. Patil R, Mittal A, Raghavia M', Malhotr A V, Srinivasaragavan, Nikhil M, Harish. A Study of Sleeping Habits and Disorders Among School Students Of Pondicherry. Journal of Clinical and Diagnostic Research. 2010;4(1):2036-2040.

10. Gupta R, Bhatia MS, Chhabra V, Slrarma S; Dahiya D, Sernalti K, Sapra R, Dua RS. Sleep patterns of urban school-going adolescents. Indian Pediatr. 2008;45(3):183-9.

11. Bano R, Awad WM (2017) Study on the Evaluation of Average Daytime Sleepiness among Female College Students using ESS Questionnaire. J Sleep Disord Treat Care. 6(1). doi: 10.4172/2325-9639.1000187

12. Kaneita Y, Ohida T, Uchiyama M, et al. Excessive daytime sleepiness among the Japanese general population. J Epidemiol. 2005;15(1):1-8.

13. Wu S, Wang R, Ma X, Zhao Y, Yan X et al. (2012) Excessive daytime sleepiness assessed by the Epworth Sleepiness Scale and its association with health related quality of life: a population-based study in China. $B M C$ Public Health. 12:849. doi:10.1186/1471-2458-12-849.

14. Johns MW. Daytime sleepiness, snoring, and obstructive sleep apnoea. The Epworth Sleepiness Scale. Chest. 1993;103(1):30-6.

15. Pallos H, Yamada N, Doi Y, Okawa M. Sleep habits, prevalence and burden of sleep disturbances among Japanese graduate students. Sleep Biol Rhythms. 2004;2(1)37-42.

16. Rodrigues RN, Viegas CA, Abreu E Silva AA, Tavares P. Daytime sleepiness and academic performance in medical students. Arq Neuropsiquiatr. 2002;60(1):6-11.

17. Murray W Johns. The Epworth Sleepiness Scale. epworthsleepinessscale.com/about-the-ess/

18. Meyer C, Ferrari GJ, Barbosa DG, Andrade RD, Pelegrini A, Felden ÉPG. Analysis of daytime sleepiniess in adolescents by the pediatric daytime sleepiness scale: a systematic review. Revista Paulista de Pediatria. 2017;35(3):351-360. doi:10.1590/19840462/;2017;35;3;00015.

19. Ahmed S Bahamman, Omar K AL-Khairy, Ahmed A AL-Taweel. Sleep habits and patterns among medical students. Neurosciences. 2005;10(2):159-62.

20. Zailinawati AH, Teng CL, Chung YC, Teow TL, Lee PN, Jagmohni KS. Daytime sleepiness and sleep quality among Malaysian medical students. Med J Malaysia. 2009 Jun;64(2):108-10.

\footnotetext{
How to cite this article: Veena CN, Meghana T, Vastrad BC, Nandan TM. Evaluation of day time sleepiness using Epworth sleepiness score among medical students. Ind J Clin Anat Physiol. 2018;5(3):422-424.
} 